\title{
Notas sobre o nascimento da historiografia moderna no Japão da Era Meiji*
}

\author{
Notes on the birth of modern historiography in Meiji's Japan
}

\author{
Rômulo da Silva Ehalt \\ romuloehalt@gmail.com \\ Doutorando \\ Universidade de Estudos Estrangeiros de Tóquio \\ Tokyo-to Fuchu-shi Asahicho 3-11-1 \\ $183-8534$ \\ Japão
}

\section{Resumo}

Este trabalho oferece um panorama sobre o processo de formação e desenvolvimento das ciências históricas no Japão durante o processo de abertura ao Ocidente na Era Meiji. O objetivo é refletir sobre processos específicos do caso japonês, como a "história das civilizações" de Fukuzawa Yukichi, a divisão da área em História Nacional (Kokushi), Oriental (Tōyōshi) e Ocidental (Seiyōshi) etc., a partir da história institucional dos locais de produção de história no país e de movimentos historiográficos japoneses oitocentistas. Para esta pesquisa foram levantadas fontes da época e consultada literatura secundária. O trabalho conclui chamando a atenção para a originalidade das interpretações da metodologia ocidental feitas no país durante o século XIX e a autocrítica entre historiadores japoneses em relação às ideologias do país existentes desde antes de sua abertura ao Ocidente.

\section{Palavras-chave}

História da Historiografia; Japão; Cultura histórica.

\begin{abstract}
This paper gives an overview on the Japanese historical sciences' formation and development process during the process of opening to the West, in the Meiji Era. Approaching institutional history of places where history was written and 19th-century Japanese historiographical movements, this work aims to reflect on specific processes of the Japanese experience, like Fukuzawa Yukichi's "history of civilization", the division into National (Kokushi), Eastern (Tōyōshi) and Western Histories (Seiyōshi) etc. This research analyses primary sources and secondary literatures. The paper concludes by drawing attention to the originality of Japanese interpretation of Western methods during the 1800's and the self-criticism present among Japanese historians in relation to the ideologies of the country since before its opening to the West.
\end{abstract}

\section{Keywords}

History of Historiography; Japan; Historical culture. 
Como se deu o processo de formação da historiografia moderna no Japão? Este artigo explora questões envolvendo o início da disciplina histórica no país durante sua modernização na segunda metade do século XIX.

Para entender melhor a formação das ciências históricas no Japão, faz-se necessária uma introdução ao contexto sociopolítico do país no período. Em 1868, a Restauração Meiji pôs fim ao governo Tokugawa e à ordem feudal. O processo iniciou-se em 1866 com a aliança entre Saigō Takamori, samurai do governo da província de Satsuma, e Kido Takayoshi, samurai da província de Chōshū ligado a movimentos radicais, e a restauração devolveu o poder central às mãos do Imperador em finais de 1867, com a renúncia do último shogun, Tokugawa Yoshinobu. A mudança de governo foi oficializada por meio de um édito imperial em 3 de janeiro de 1868.

As reformas que se seguiram causaram profundas mudanças estruturais no país. Entre elas, destacam-se a aceleração da industrialização, a criação de um exército nacional, a abolição do sistema de classes (Shinōkōshō), ${ }^{1}$ a promulgação da primeira Constituição japonesa e a reorganização do território em províncias.

\section{Tendências da historiografia na Era Meiji}

Em meio a tantas mudanças, a escrita da história não passou incólume. A modernização das instituições sociais e a introdução do pensamento ocidental causaram choque e grandes mudanças na historiografia e no modo de se pensar a história durante a Era Meiji. Schneider e Tanaka classificam o período, grosso modo, como um tempo de conflito, quando intelectuais se dividiram em grupos influenciados por dois paradigmas filosóficos distintos: a tradição historiográfica chinesa e a nova historiografia europeia (SCHNEIDER; TANAKA 2011, p. 491).

Neste contexto, é difícil determinar qual foi o pensamento hegemônico nas ciências históricas. O historiador japonês Nagahara Keiji divide os historiadores da época em quatro grupos. O primeiro representava uma continuidade do pensamento confucionista da Era Edo, reproduzindo uma visão de mundo hierarquizada; essa tendência vai afetar diretamente a política educacional do governo Meiji (NAGAHARA 2003, p. 8). Como exemplo, podemos citar Motoda Nagazane, ${ }^{2}$ oriundo da província de Higo e especialista no pensamento confucionista, que teve muita influência sobre o jovem Imperador Meiji e o processo de reestruturação do sistema educacional japonês (NUMATA; MOTODA 1985, p. 3).

O segundo grupo era composto por estudiosos da escola de filologia Han chinesa, que defendiam um revisionismo baseado em preceitos da dinastia Qīng, negando origens míticas da história e superstições do confucionismo clássico,

\footnotetext{
${ }^{1}$ Este modelo é oriundo do sistema meritocrático de classes sociais da China, descrito pela primeira vez no clássico confucionista Chūnqiū, ou Anais de primavera e outono. Este texto influenciou sociedades posteriores, e essa influência resultou, no Japão, na divisão da sociedade nas seguintes classes: guerreiros, agricultores, artesãos e mercadores; na China, Coreia e Vietnã, as quatro classes correspondiam aos burocratas (incluindo aristocracia hereditária), agricultores, artesãos e mercadores. É interessante notar a diferença desse sistema com respeito ao sistema de castas indiano, de base religiosa: no Japão, as classes são fundamentadas nas relações oriundas da divisão do trabalho. Ver capítulo 4 de WATANABE 2010.

2 Também conhecido como Motoda Eifu.
} 
e visavam ultrapassar a ordem e a filosofia feudais (NAGAHARA 2003, p. 9). Desse grupo podem-se destacar Shigeno Yasutsugu, da província de Satsuma, Kume Kunitake, de Saga, e Hoshino Hisashi, de Echigo. Eles serão os principais responsáveis dentro do governo Meiji pela compilação da história oficial, além de formarem o núcleo que, pelo estudo de métodos da historiografia ocidental, darão início à faculdade de Literatura da então Universidade Imperial (atual Universidade de Tóquio).

O terceiro grupo é o da linha xintoísta, que se posiciona nessa época na direita do mundo acadêmico e político. Esse grupo era formado por estudiosos oriundos de fora da estrutura de governo do antigo xogunato Tokugawa, indivíduos que, em sua maioria, não eram membros das antigas famílias samurai (NAGAHARA 2003 , p. 9). Falecido em 1843, antes do início da Restauração Meiji, seu principal representante foi Hirata Atsutane, que teve mais de 500 discípulos, em sua maioria sacerdotes xintoístas e membros de famílias abastadas de agricultores. Com a Restauração, esses acadêmicos aderem ao movimento de defesa do xintoísmo como ideologia de Estado, promovendo a destruição de templos budistas e uma retomada de uma visão tradicional e religiosa da história.

Por último, o quarto grupo é o da história civilizatória ou história de abertura, tendo como expoente máximo Fukuzawa Yukichi. Estudioso de artes e idiomas ocidentais, viajou três vezes à Europa e aos Estados Unidos antes do fim do xogunato, publicando em 1866 o primeiro volume de sua obra Condições do Ocidente (Seiyō Jijō). Em 1875, publica sua Descrição da teoria da civilização (Bunmeiron no Gairyaku), com ideias sobre civilização influenciadas pela obra de François Guizot Histoire de la civilization en Europe, de 1828, e por autores como Alexis de Tocqueville, Herbert Spencer e Henry Buckle (KADOWAKI 1961, p. 171). Além de Fukuzawa, o jovem Taguchi Ukichi publica, entre 1877 e 1882, sua Pequena história da civilização do Japão (Nihon Kaika Shōshi), tornandose uma das figuras centrais do grupo da história civilizatória. Estes intelectuais serão alguns dos responsáveis pela modernização da ciência historiográfica no Japão (NAGAHARA 2003, p. 9).

Schneider e Tanaka chamam a atenção para a natureza do conflito entre esses grupos. Fukuzawa, Taguchi e outros defendiam uma história universal, com novas ideias ocidentais reinterpretadas pelos japoneses, enquanto grupos conservadores carregavam consigo uma tradição empiricista confucionista que os prendia ao registro de datas e fatos. Essas duas vertentes atuavam em meio a um dilema em função do qual a necessidade de se distanciar do passado para tornar-se moderno e narrar o passado para transformá-lo em parte do moderno requeria de uma configuração mais complexa do que a simples transição do velho para o novo (SCHNEIDER; TANAKA 2011, p. 495). Podemos dizer que, enquanto a tradição historiográfica chinesa demandava a escrita de uma história do passado para legimitar a passagem de poder a uma nova dinastia, os historiadores japoneses viviam um momento de separação do seu presente com o passado. A história foi congelada e rotulada como tradição a fim de libertar o tempo presente das amarras do passado e dar maior abertura às profundas mudanças do país. Dentro desse novo contexto, a história assume, como 
afirma Margaret Mehl, um papel político no recém-formado Estado moderno japonês, sendo responsável pela formação de uma identidade nacional e pelo entendimento da elevação do Japão ao seleto grupo de potências do fim do século XIX (MEHL 2003, p. 183).

\section{Disputas ideológicas}

Um dos principais palcos do conflito entre essas linhas de pensamento foi a chamada "história oficial" (Seishi). Seguindo a tradição chinesa de legitimação do governo por meio de uma história reconhecida pelo Estado, o governo Meiji cria em 1869 o Escritório de Registros Históricos (Shūshikyoku). O texto da ordem imperial de criação desse departamento é marcadamente confucionista, declarando como função do Escritório "a correção das relações hierárquicas e o esclarecimento dos limites entre civilização e barbárie". ${ }^{3}$ Margaret Mehl considera que a opção pela tradição chinesa mostra que o Estado Meiji considerava como seu dever a escrita da história para legitimação do regime, e, enquanto o modelo burocratizado de Estado imperial era tido como ideal para o novo governo, a história oficial era vista como ideal para a historiografia (MEHL 2003, p. 184). Parece-nos que essa opção revela uma necessidade muito maior do Japão de ser visto como legítimo também pelos seus vizinhos para a manutenção das relações exteriores. E são justamente as relações com a China, a Coreia, etc. que vão determinar a opção pela tradição chinesa, reconhecida e legitimada internacionalmente pelo regime imperial chinês, em detrimento de uma total adoção de novos modelos ocidentais, oriundos de países com os quais as relações ainda eram novas e pouco amadurecidas.

Em 1870, iniciam-se as atividades do Departamento de Edição de Registros Históricos (Kiroku Henshū Gakari), ${ }^{4}$ responsável pela coleção e edição de documentos históricos, seguindo uma cronologia chinesa; esse trabalhou distou muito do que poderia ser caracterizado como historiografia moderna (SCHNEIDER; TANAKA 2011, p. 496). Contudo, durante seus primeiros anos de atividade, o departamento dedica-se à edição dos chamados "Registros da Restauração" (Fukkoki), o que demonstra a preocupação e urgência do governo em buscar legitimidade histórica para a predominância novo do regime imperial sobre as antigas formas de organização e soberania do período do xogunato (NAGAHARA 2003, p. 12). Já Margaret Mehl aponta que essa atividade de coleta de documentação teria muito mais a ver com o cenário político daquele momento do que com uma preocupação histórica (MEHL 2003, p. 185). Se analisarmos as primeiras grandes mudanças estruturais da Restauração Meiji, deparamo-nos com a grande reorganização do território japonês de 1871, que acabou com as antigas províncias do período Edo (chamadas de "han") e reorganizou a divisão em novas províncias, ken e $f u$, subordinadas ao governo central e com menos autonomia do que no modelo anterior. A partir dessa reorganização,

\footnotetext{
3 Édito Imperial de 3 de maio de 1869, no arquivo do Instituto Historiográfico da Universidade de Tóquio, fundo Documentos Essenciais da Restauração, Vol. 10, fólio 78.

4 Este departamento, assim como o Escritório de Registros Históricos, passou por diversas mudanças de nomenclatura e posição dentro da estrutura organizacionail do governo Meiji.
} 
cada província dedicou-se a contribuir para a edição de um relatório topográfico sobre seu território, muito mais voltado à edição de informações administrativas do que à compilação histórica. Esse relatório, chamado Kōkoku Chishi (Relatório Topográfico do Império), nunca foi publicado, e mais da metade dos cerca de 6.400 volumes de documentos foi perdida durante o terremoto de Tóquio de 1923 (ISHIDA 1966, p. 1-61).

Cinco anos após sua criação, Shigeno Yasutsugu assume o departamento e contrata novos profissionais, chegando a coordenar 80 pessoas na edição de fontes históricas. Nagahara considera esse o ponto de partida para a moderna historiografia japonesa (NAGAHARA 2003, p. 12). Mas, como alertam Schneider e Tanaka, não podemos esquecer que esse processo levou décadas para ser concluído, e considerar esses primeiros anos depois da Restauração Meiji como início da historiografia moderna no Japão seria incorrer em erro (SCHNEIDER; TANAKA 2011, p. 494).

É claro que essas conclusões surgem de noções diferentes do que poderia ser declarado historiografia moderna: algo terminado, a ser reconhecido somente no momento em que reúne um certo grupo de características de método e conceitos, ou como processo no qual a presença dessas características lentamente se faz perceber e fatores mais antigos, herdados da tradição chinesa, podem ser reconhecidos ainda em momentos mais tardios.

Ao analisarmos os participantes desses primeiros passos da formação da historiografia moderna no Japão, podemos averiguar que eles vinham de linhas de pensamento diferentes e até então antagônicas, como visto acima. Mas é a partir das atividades exercidas por esse departamento que o governo escolheria sua visão oficial de história. Por reunir diferentes experiências e carregar a marca da mudança conferida pelo regime Meiji, podemos chamar essa visão de história de "moderna", especialmente pelo fato de tais historiadores considerarem seu ofício diferente dos métodos e concepções moralistas que a tradição historiográfica chinesa da era do regime Tokugawa defendia.

O trabalho dos historiadores oficiais do governo Meiji enfrentou questões metodológicas desde seu princípio. Nagahara Keiji chama a atenção para quatro problemas básicos. Em primeiro lugar, a função desses profissionais: coletar e editar documentos históricos, como defendido na época por Kawada Tsuyoshi, ou analisar fontes para a escrita da história oficial, tal como defendido por Shigeno Yasutsugu? Em seguida, qual período deveria servir de ponto de partida para o trabalho? Em terceiro lugar, o modelo a ser adotado: edição de crônicas históricas no modelo chinês, ou escrita da história com base no modelo historiográfico europeu? Por fim, a história oficial deveria ser escrita em kanbun ou wabun, isto é, em chinês clássico ou no idioma japonês? (NAGAHARA 2003, p. 13-14). É importante frisar que o chinês clássico não era visto como um idioma estrangeiro, mas sim como a língua de estudos clássicos, com função semelhante ao latim dentro do mundo intelectual europeu desse período.

Por trás dessa disputa, iniciada com a convivência de Shigeno e Kawada dentro do governo, estava a questão do uso e dos limites da história. Para Kawada, a história não deveria se preocupar em investigar detalhes e trazer 
à tona eventos que poderiam ser prejudiciais ao governo ou à hierarquia predominante, submetendo a pesquisa a ideais confucionistas. Shigeno, por outro lado, ia de encontro a essa posição, defendendo um positivismo racional (NAGAHARA 2001, p. 14), ou seja, uma organização do conhecimento histórico com ênfase em fatos e datas do modo como são descritos na documentação histórica. Podemos dizer que a rixa entre os dois representava o debate sobre o abandono de uma visão feudal japonesa da escrita da história em prol de uma historiografia moderna.

Em 1877, ingressa ao departamento Kume Kunitake, historiador da mesma linha de pensamento de Shigeno Yasutsugu que havia acompanhado a embaixada oficial de Iwakura Tomomi aos Estados Unidos e à Europa entre 1871 e $1873^{5}$ e editado o registro oficial da embaixada (Beiō Kairan Jikki, Relatórios das visitas à Europa e aos Estados Unidos). Com a entrada de Kume Kunitake, o grupo de estudiosos revisionistas da filologia Han chinesa torna-se hegemônico na escrita da história oficial. Finalmente, com a saída de Kawada Tsuyoshi, Shigeno dá início aos trabalhos de elaboração da história oficial em 1882.

É definido então que a história oficial (Seishi) do governo Meiji seria escrita em chinês clássico e deveria começar, por ordem do imperador, onde terminam as chamadas Rikkokushi, ou "Seis histórias nacionais", que abrangem o começo da história japonesa até o ano de 887. Essas escolhas podem ser entendidas dentro da necessidade de legitimação do novo regime imperial frente a outras nações asiáticas, resultando em um relato com fins oficiais, em detrimento da adoção de métodos modernos de escrita da história. Além disso, elas representam uma continuação dos métodos confucionistas tradicionais de escrita da história, considerando esse trabalho herdeiro das antigas crônicas do estado japonês.

\section{Problemas da história oficial}

O processo de formação da historiografia moderna começa no Japão com a história oficial, isto é, uma história editada de acordo com os interesses do regime. A decisão de escrever a história a partir das escolhas de seus burocratas logicamente não tem sua origem em um pensamento moderno de historiografia, mas sim na tradição chinesa de escrita da história, voltada à legitimação do novo regime. Apesar disso, Shigeno tem desde o princípio a preocupação em eliminar quaisquer juízos de valor ligados a linhas de pensamento confucionistas clássicos, feudais e hierarquizantes da sociedade (NAGAHARA 2003, p. 16). Neste ponto podemos identificar uma preocupação moderna com a escrita da história por uma tomada de posição crítica em relação ao objeto. Em conferência proferida em 1879, Shigeno reconhece o risco existente de se escrever uma história conveniente ao poder quando se está tão próximo dele (SHIGENO 1991b, p. 213-221).

\footnotetext{
${ }^{5}$ O governo Meiji enviou à Europa e aos Estados Unidos uma missão diplomática de mais de 100 membros, incluindo Iwakura Tomomi como embaixador e Ōkubo Toshimichi, Kido Takayoshi, Itō Hirobumi e Yamaguchi Masuka como vice-embaixadores. O grupo partiu de Yokohama e visitou os EUA, a Inglaterra, a França, a Bélgica, a Holanda, a Rússia, a Alemanha, a Prússia, a Dinamarca, a Suécia, a Austria, a Itália, o Egito, o Ceilão, Cingapura, Saigon, Hong Kong e Xangai, entre outros. O objetivo era renegociar tratados considerados prejudiciais ao Japão firmados com países como os EUA e a Inglaterra e reunir informações sobre tecnologia, cultura, organização militar, etc., para acelerar a modernização do Japão.
} 
Na mesma conferência, Shigeno reconhece na historiografia ocidental uma maior liberdade e franqueza, visto não estar presa a uma escrita cronológica da história e não se preocupar em ocultar fatos incômodos ao governo, além de uma maior capacidade de análise (SHIGENO 1991b, p. 213-221). Entretanto, essa historiografia ocidental a que ele se refere não é exatamente a história das civilizações apreciada por Fukuzawa Yukichi, mas sim obras como The Satsuma Rebellion: An Episode of Modern Japanese History, do diplomata inglês Augustus Henry Mounsey, ou, ainda, a Histoire de l'Église du Japon, do jesuíta francês Jean Crasset. Enquanto Mounsey pode ser citado como um historiador moderno, tendo sua obra publicada em inglês em 1879, Crasset publicou sua obra em 1689, o que, para nós, mostra que, mesmo para um pesquisador de altíssimo nível como Shigeno, o acesso a obras de história ocidentais era escasso e arbitrário, e mesmo trabalhos como o de Crasset só puderam ser recebidos depois da reabertura do país.

A fim de se aprofundar no método historiográfico ocidental, Shigeno pede o envio de um representante para a Europa (NAGAHARA 2003, p. 17-18). É escolhido então Suematsu Kenchō, que parte para a Inglaterra e a França, onde fica de 1878 a 1886. Sob orientação do húngaro Gustav Zerffi, Suematsu estuda e colige dados sobre a metodologia ocidental. Zerffi escreve então em inglês a obra História (Shigaku), que é traduzida por Suematsu (ZERFFI 1991, p. 260-272; TANAKA et al. 1991, p. 493-494), enviada ao Japão e recebida por Shigeno. ${ }^{6}$ Contudo, o trabalho de Zerffi é mantido inédito e acaba não tendo influência na metodologia historiográfica no Japão. Margaret Mehl cogita que isso teria distanciado métodos ocidentais e reiterado a tradição historiográfica na história japonesa (MEHL 2003, p. 186). De qualquer modo, a pouca influência de Zerffi não precisa ser entendida necessariamente como renovação de valores da tradição historiográfica japonesa. Shigeno foi grande crítico dos métodos tradicionais, chamando-os de "limitados aos indivíduos e ao particular", sem se preocupar com a análise do contexto político, social ou econômico (SHIGENO 1991b, p. 217). Schneider e Tanaka chamam a atenção para o fato de que, durante sua carreira, Shigeno passou a criticar a própria veracidade das fontes, chegando a classificar crônicas históricas como mitos e a duvidar da existência de personagens como Kusunoki Masashige e Kojima Takanori (SCHNEIDER; TANAKA 2011, p. 497).

\section{A história da civilização}

Enquanto o grupo liderado por Shigeno Yasutsugu se ocupava da escrita da história oficial, forma-se em 1873 o grupo Meirokusha, ${ }^{7}$ composto por Fukuzawa Yukichi, Mori Arinori, Katō Hiroyuki e outros estudiosos com grande conhecimento de línguas estrangeiras. Incluindo especialistas de vários campos, o objetivo era traduzir e publicar obras acadêmicas do exterior a fim de edificar e divulgar conhecimento no Japão (NAGAHARA 2003, p. 20). Mas é importante

\footnotetext{
${ }^{6}$ A tradução original de Suematsu encontra-se no fundo documental "Shigeno Yasutsugu" do Instituto Historiográfico da Universidade de Tóquio.

${ }^{7} \mathrm{O}$ nome do grupo deriva do fato de ter sido fundado no ano 6 da Era Meiji.
} 
ressaltar que, como diz Tanaka, esse interesse por ideais ocidentais não significa que suas ideias fossem liberais, mas sim que esse novo conjunto de paradigmas universais substituíram a China clássica como modelo ideal (TANAKA 1993, p. 36). Enquanto, para outros grupos, a China permanecia como modelo moral idealizado, para Fukuzawa e seu grupo, a história universal seria o modelo de progresso e modernidade, e reler o Japão dentro desse formato era essencial para mudar o país.

Em 1874 é publicada a Histoire Générale de la Civilisation en Europe, de Guizot, obra muito influente no pensamento de Fukuzawa e traduzida para o japonês por Nagamine Hideki. Inspirado por Guizot, Mitsuku Rinshō escreve, com base em autores ingleses e franceses, a obra Nova história do mundo (Bankoku Shinshi), publicada entre 1871 e 1876 (NAGAHARA 2003, p. 20).

Obras como Descrição da teoria da civilização e Condições do Ocidente, de Fukuzawa Yukichi, ganhavam espaço e mentes. O impressionante número de vendas de Condições... (publicado entre 1866 e 1870), calculado em algo entre 150 a 250 mil exemplares, mostra que, antes mesmo do governo iniciar sua política de abertura ao Ocidente, o interesse da população pela cultura ocidental era muito grande.

Esse elevado interesse pelo exterior certamente foi influenciado por fatos marcantes do século XIX, como a Guerra do Ópio, a chegada de navios estrangeiros, a abertura do país, o firmamento de tratados injustos com nações estrangeiras, etc. (TANAKA et al. 1991, p. 510-514). Tudo isso contribuiu para

126 um clima de ameaça que se reverteu, através das elites literárias, em uma visão fechada de história para grupos conservadores e em estímulo para a incorporação do Japão à história universal, para Fukuzawa, Taguchi e outros.

Alguns estrangeiros no Japão na época registraram esse "fervor pelo Ocidente" como um aparente "desinteresse" dos japoneses pelo seu próprio passado. O médico alemão Erwin von Bälz registrou em seu diário em 25 de outubro de 1876 que "os japoneses de hoje em dia não querem mais saber de seu passado. [...] Me dizem 'nós não temos história, nossa história vai começar agora!'" (SATŌ et al. 2008, p. 391). Esse pensamento representa aquilo que podemos chamar de "congelamento" do passado como tradição, visando libertar o presente do peso de sua história e permitir mudanças estruturais profundas na sociedade, como, por exemplo, a da promulgação da constituição Meiji em 1889.

Para os historiadores da civilização, a questão era mais do que desinteresse pelo que fosse japonês e absorção cega do que fosse estrangeiro. O objetivo desses intelectuais era rever a história do Japão como nação dentro do mundo e avaliar as possibilidades dessa mesma nação de estudar e se aproximar de países considerados mais avançados como os Estados Unidos e os países europeus. Podemos dizer que essa questão fez com que a visão de história na primeira metade da Era Meiji fosse ao mesmo tempo universalista e progressivista.

Fukuzawa Yukichi define em sua Descrição da teoria da civilização a evolução da civilização como concretização do eixo motor da história. Para ele, a libertação psicológica dos homens das travas sociais, a liberdade de ofício 
para os indivíduos e a ampliação das liberdades pessoais possibilitam o processo civilizatório. Analisando a história, Fukuzawa vê a sociedade como parte de um processo em três estágios: barbárie, semicivilização e civilização (TANAKA et al. 1991, p. 494; FUKUZAWA 1875, Seção 1 cap. 2 e Seção 3 cap. 6). Na sua visão, a Era Edo representa o período de semicivilização, e as sociedades avançadas do Ocidente, o estágio da civilização. A história da civilização defendida por Fukuzawa não é a história de apenas um país, mas sim uma teoria geral de características e leis universais da evolução que ultrapassam fronteiras. Segundo Tanaka, muitos, incluindo Fukuzawa, acreditavam no fim das guerras como ponto máximo a ser buscado pelas civilizações. A evolução histórica por meio de revoluções resultaria no fim de todos os conflitos e na libertação intelectual do espírito humano. E o Japão teria papel fundamental nesse processo civilizatório na Ásia (TANAKA et al. 1991, p. 489-490). O cenário de desmonte da estrutura do xogunato Tokugawa e a construção do Estado moderno Meiji parecem ter facilitado a aceitação pelos intelectuais da época dessa proposta de evolução histórica e universalidade da civilização.

Apesar de não ser considerado um historiador, Fukuzawa Yukichi é responsável por formular no Japão a análise da história por esse viés evolutivo. Como alertam Schneider e Tanaka, sua obra Descrição da teoria da civilização trata-se muito mais de um argumento que incorpora o arquipélago japonês à marcha do progresso da civilização do que de um livro de história propriamente dito (SCHNEIDER; TANAKA 2011, p. 495). A Fukuzawa se deve ainda a visão que atribuiu características feudais à Era Edo e igualou a Era Meiji à modernidade, além da qualificação no Japão da evolução da história da civilização como algo geral da história humana, universal e regular (NAGAHARA 2003, p. 22).

Como mencionado anteriormente, tão importante quanto Fukuzawa Yukichi nesse período é a obra de Taguchi Ukichi. Taguchi começa sua carreira de historiador do movimento de história da civilização com sua Pequena história da civilização do Japão, publicada em 1877, e seguida no ano seguinte por sua obra mais conhecida, Estudo de comércio livre e economia do Japão (Jiyū Kōeki Nihon Keizai Ron). Além de suas teses, Taguchi funda duas revistas, a Revista de economia de Tóquio (Tōkyō Keizai Zasshi) e a Oceano de história (Shikai), ambas ainda editadas hoje. Por fim, ele também foi o responsável no fim de sua vida pela edição e publicação da coleção Panorama de história nacional (Kokushi Taikei), que apresenta documentos funamentais ao estudo da história japonesa, acrescidos de comentários e explicações.

O grande mérito da obra de Taguchi é que, baseado nos exemplos de Guizot e de outros autores estrangeiros, ele conseguiu estabelecer um fio condutor da história japonesa desde a Antiguidade até a Era Meiji. Os métodos de pesquisa histórica, iniciados na Era Edo, resumiam-se a reinterpretações de textos clássicos e catalogação precisa de eventos e personalidades. Taguchi supera essa visão e identifica no desenvolvimento econômico o grau de civilização de cada época. Como diz Nagahara, nesse ponto ele difere grandemente de Fukuzawa, que considerava o nível de conhecimento humano o parâmetro do grau de civilização (NAGAHARA 2003, p. 24-25). 
Chamado de "o Adam Smith japonês", Taguchi define a história como a evolução da habilidade do homem em obter riquezas, redefinindo assim a visão que se tinha de épocas consideradas sombrias da história japonesa, como o período das duas Cortes Norte e Sul no século XIV e o período de guerra civil do século XV ao final do XVI. Para Taguchi, a força motriz da história encontra-se no desejo de autopreservação humana, na luta por "proteger a vida e evitar a morte" (Sei wo tamochi Shi wo saken) (TAGUCHI 1877-1882, cap. 11). Para vencer, as pessoas põem em prática o conhecimento e, como resultado, as mudanças registradas na forma de acumulação de riquezas se refletem no estado psicológico pessoal. Logo, a história é a história da evolução da sociedade, e esta pode ser compreendida por uma visão e uma teoria, ambas regulares e universais. Entre as linhas de pensamento historiográfico que podem ser identificadas neste período, podemos destacar o campo inaugurado por Taguchi pela capacidade analítica e universalizante de conceitos para toda a história do Japão.

As propostas de Taguchi influenciam, junto com as ideias de Fukuzawa, o ramo hegemônico das ciências históricas no Japão. Desde então, perde força a escola positivista academicista de Shigeno Yasutsugu, e, ao se analisar todo o período de formação das ciências históricas no Japão, é possível perceber que as propostas de Taguchi e Fukuzawa tiveram um profundo e permanente impacto na teoria e na metodologia histórica do país.

\section{Ludwig Riess e Kume Kunitake}

Shigeno Yasutsugu e seu grupo de historiadores do governo enfrentavam dificuldades cada vez maiores (NAGAHARA 2003, p. 32-33). O regime Meiji passou a ver como retrógradas as escolhas feitas pelo grupo, refletindo modelos chineses que não condiziam com o projeto de aproximação do Japão às nações desenvolvidas e iam na contramão da objetificação da China e do Oriente como um passado idílico a ser superado. Em 1885, o departamento de registros históricos é fechado, e suas incumbências são repassadas à recém-criada Universidade Imperial (atual Universidade de Tóquio).

Herdeira da Escola Kaisei de Tóquio, a universidade era composta por cinco faculdades: Direito, Medicina, Engenharia, Literatura e Ciências. Para completar os quadros de professores e atualizar o ensino superior no país, o governo convida estrangeiros para lecionar na universidade. Entre eles está Ludwig Riess, alemão formado pela Universidade de Berlim e discípulo de Leopold von Ranke.

Riess chega ao Japão em 1887 incumbido de ensinar na Universidade Imperial métodos ocidentais de historiografia, como o uso de fontes primárias, a ênfase na história narrativa e a busca por uma história neutra, isenta de juízos de valor. Durante seus 15 anos no país, ele ensinou ainda na Universidade Keiō disciplinas como História de Taiwan, História da Europa moderna, História alemã, Revolução Francesa, etc. Riess também foi um dos primeiros a apresentar à academia japonesa fontes ocidentais relacionadas à história do Japão, existentes em arquivos de Haia, Londres e Roma (NAGAHARA 2003, p. 33; KANAI 1976, p. 149-163). 
Ainda em 1887, é fundado na Universidade Imperial o Departamento de Ciências Históricas (Shigakuka), focado no estudo da história ocidental. No ano seguinte, a universidade assume as funções do departamento oficial de história, trazendo para o quadro de professores da universidade os profissionais que trabalhavam na elaboração da história oficial junto com Shigeno Yasutsugu. Como resultado, em 1889 é inaugurado, dentro da faculdade de Literatura, o primeiro Departamento de História Nacional (Kokushika), sendo esse um dos marcos na história da historiografia japonesa (NAGAHARA 2003, p. 33). Podemos considerar esse o momento a partir do qual métodos de historiografia ocidental são aplicados diretamente às fontes da história japonesa, da mesma forma que eram aplicados a países do Ocidente. Para Schneider e Tanaka, o trabalho do historiador no Japão passou a ser cuidadoso; de metodologia mecânica, análise e conexão de dados do passado, para a construção de uma narrativa geral (SCHNEIDER; TANAKA 2011, p. 499).

Contudo, Mehl argumenta que essa aplicação de métodos ocidentais era aparente. Questionando a influência de Riess e da historiografia alemã, ela chama a atenção para o perigo da supervalorização de tal influência, o que levaria o leitor a ignorar a tradição historiográfica japonesa, que já contava com elementos de crítica textual e escrita de narrativas muito antes da chegada de Riess (MEHL 2003, p. 183). Podemos dizer que a tradição historiográfica chinesa, por sua vez, teve uma influência muito maior e que a modernização dos métodos de escrita da história do Japão, ainda que impulsionada e influenciada pela chegada dos métodos ocidentais, deu-se a partir da modificação da metodologia já em prática no país.

No mesmo ano da inauguração do Departamento de História Nacional, Riess orienta o grupo fundador da primeira Associação de História do Japão (Shigakkai), e Shigeno Yasutsugu é escolhido como primeiro presidente. Tal associação apressa-se a lançar, ainda em 1889, a Revista da Associação de História (Shigakkai Zasshi) (NAGAHARA 2003, p. 34).

Na primeira reunião da Associação, Shigeno palestra para cerca de 200 novos membros. Ciente de como a pesquisa histórica pode sofrer com a política, a preocupação principal do discurso de Shigeno é a imparcialidade na escrita da história: "O historiador deve ter a mais imparcial das mentes, deve sempre se preocupar com seus preconceitos e opiniões" (SHIGENO 1991a, p. 273274). ${ }^{8}$ Podemos dizer que a formação de Shigeno no confucionismo revisado, de forte crítica textual dos clássicos chineses, levou-o a uma aproximação por semelhança com a historiografia ocidental ao longo de sua carreira.

Outra figura central do período é Kume Kunitake. Desde os primeiros números da Revista da Associação de História, Kume publica textos provocadores, com o objetivo de forçar definitivamente o fim de uma ideologia feudal-confucionista a favor da modernidade.

Entre seus textos, o mais polêmico certamente foi "O xintoísmo é um rito antigo" (Shintō ha saiten no kozoku), publicado em 1891. Esta tese foi

\footnotetext{
${ }^{8}$ No original: Rekishika ha mottomo kokoro wo kōhei ni shite, henken shii wo kaisezaru wo tsutomubeshi.
} 
a primeira a apresentar o xintoísmo em uma visão objetiva, como objeto histórico, retratando-o como religião e criticando a atuação da extrema direita da academia e do governo que o defendiam como ideologia de Estado. Ao classificar o xintoísmo como culto antigo, comum a todos os povos, Kume exime o caso japonês de qualquer característica que o torne especial em relação a outras nações, atacando o núcleo sobre o qual se fundamentava todo o ideário estatal do regime (KUME 1991, p. 445-466).

O objetivo de Kume era compreender a religião japonesa como fenômeno dentro do contexto histórico do Leste Asiático, contextualizando o xintoísmo, esvaziando-o de sentido mítico. Seu impacto na época foi tão grande que atraiu a atenção de Taguchi Ukichi, que fez questão de republicar o texto em sua revista, Oceano de história, em janeiro de 1892 (KUME 1991, p. 445-446). O governo não pode se manter calado e afasta Kume Kunitake da Universidade Imperial, ordena o recolhimento das revistas e, em 1893, afasta da universidade Shigeno Yasutsugu e outros do mesmo grupo. O episódio colocou em questão a ligação das ciências históricas com a ideia japonesa de nação (Kokutai) e pôs em dúvida a liberdade acadêmica no Japão em um período de acirramento da ideologia xintoísta e repressão por parte do governo Meiji a vozes contrárias (TANAKA et al. 1991, p. 550-554; NAGAHARA 2003, p. 36-38).

\section{Reorganização do campo da história}

Toma então força uma vertente xintoísta nacionalista, justo no momento

130 em que se estrutura o ensino escolar de história. Quanto aos ex-membros da Universidade Imperial, Shigeno Yasutsugu se aposenta, enquanto Kume Kunitake acaba sendo integrado ao quadro de professores da então Escola Profissionalizante de Tóquio (atual Universidade Waseda).

A vertente positivista da história japonesa acaba enfraquecida e, posteriormente, une-se aos historiadores da civilização do grupo de Fukuzawa Yukichi. Passam a defender a liberdade acadêmica em relação ao poder político, e, apesar de terem representado a principal escola historiográfica do século XIX no Japão, o incidente com o texto de Kume enfraquece politicamente o grupo. Assume então o comando da Universidade Imperial e do renovado Instituto Historiográfico (Shiryō Hensan Gakari, atual Shiryō Hensan-jo) um grupo de historiadores ligados ao Ministério da Educação e de forte tendência xintoísta nacionalista (NAGAHARA 2003, p. 40-42). Esse grupo está muito mais ligado à corrente da literatura nacional (kokubungaku) que, segundo Schneider e Tanaka, apostava na exatidão dos fatos e na relação causal entre eles a fim de lançar luz sobre o curso da nação (SCHNEIDER; TANAKA 2011, p. 500).

O governo encarrega esse novo grupo de coletar e editar fontes históricas, deixando a descrição e a narrativa histórica ao trabalho individual. Segundo Nagahara, o projeto consiste na publicação de todos os cerca de 130 mil documentos coligidos desde o início das atividades do Departamento de Registros Históricos do governo Meiji (NAGAHARA 2003, p. 40-41). Começa então em 1901 a publicação das coleções Documentos do Japão (Dai Nihon Shiryō), com foco em fontes ligadas à administração pública, e Documentos paleográficos 
do Japão (Dai Nihon Komonjo), ambas compostas por séries de acordo com seu período histórico. As duas coleções continuam sendo publicadas até hoje. A coleção Documentos do Japão, apesar de centrada em assuntos políticos e diplomáticos, inclui ao final de cada ano publicado uma série de documentos avulsos, verdadeira miscelânea documental relativa à economia, sociedade e vida cotidiana.

A publicação de fontes editadas certamente foi inspirada pela série alemã Monumenta Germaniae Historica. Mas a iniciativa de publicar documentos históricos não era novidade no Japão. Durante o período Edo séries semelhantes foram editadas, como as coleções Gunsho Ruijū (Compilação de escritos) e Shoku Gunsho Ruijū (Segunda compilação de escritos). As novas publicações do século XIX e começo do século XX possuem vários pontos em comum com os métodos de edição utilizados nessas séries mais antigas. Por exemplo, o tema (história política) e documentos que possuem falas do imperador têm seu sujeito abreviado. Margaret Mehl afirma que os motivos por trás da iniciativa podem ser os mesmos da MGH (legitimação de um Estado recém-formado), mas os métodos aplicados são fortemente tradicionais (MEHL 2003, p. 192).

Nas últimas décadas do século XIX, o Japão passa por uma mudança ideológica, abandonando o clima de aprendizado de métodos e aspectos da cultura ocidental em prol do nacionalismo. A guerra sino-japonesa, de 1894 a 1895, e mais tarde a guerra russo-japonesa, de 1904 a 1905, aceleram o crescimento econômico, e as vitórias nos conflitos alimentam ideias de superioridade racial. Podemos dizer que, em meio a esse contexto, o Japão se separa ideologicamente da Ásia e, por consequência, da China, seu grande modelo ideal. Nagahara nos conta que o historiador Naka Michiyo defende nesse momento a criação de um campo específico para a história oriental (Tōyōshi). Em 1904, é criado na Universidade Imperial de Tóquio9 o Departamento de História Chinesa (Shina Shigaku), renomeado em 1910 Departamento de História Oriental ( $T \bar{y} y \bar{o}$ Shigaku), abarcando não apenas a história da China mas também de toda a Ásia (NAGAHARA 2003, p. 43). Segundo Tanaka, outro influente pensador do começo da história oriental foi Shiratori Kurakichi, um dos responsáveis pela passagem da crítica de textos clássicos chineses para a formulação de uma narrativa histórica (SCHNEIDER; TANAKA 2011, p. 502; TANAKA 1993, p. 24-26). Nesse momento, a cultura e a história da Ásia são vistas como uma continuação do Japão, e é a partir desse ponto de vista que se constrói um pan-asianismo dentro da academia japonesa.

É interessante notar que essa ideia de Oriente não inclui o Japão. Formam-se neste período dois "outros": a Europa, que representa o outro com o qual o país se compara, e o Oriente, personificado pela figura da China clássica e transformado em um tempo e um espaço idealizados dos quais o Japão teria se originado. Essa China se separa ainda da China real, especialmente depois da derrota da dinastia Qing na guerra sino-japonesa. Para Stefan Tanaka, alguns historiadores japoneses desse período, como Okakura Tenshin e Shiratori Kurakichi, usaram

\footnotetext{
${ }_{9}^{9}$ Assim renomeada em 1897 com a criação da Universidade Imperial de Kyoto (Kyōto Teikoku Daigaku).
} 
a história para criar uma "supraclasse, um caráter eterno" tipicamente asiático ou oriental ao qual se deveria retornar em contraposição à cultura ocidental. Tal passado "gentil, de moral ética, harmonia e comunalismo" lembra em muitos aspectos a historiografia romântica europeia dos séculos XVIII e XIX, ao mesmo tempo em que serve de medida para avaliar o desenvolvimento da sociedade japonesa (TANAKA 1993, p. 11-13, 23). É possível traçar um paralelo entre esse Oriente construído pelos japoneses do fim do século XIX e o Oriente dos orientalistas europeus descrito por Edward Said, no sentido de que tanto o Japão quanto a Europa estavam conectados por razões históricas a esse passado, mas, como lembram Schneider e Tanaka, sempre à frente no desenvolvimento civilizacional (SCHNEIDER; TANAKA 2011, p. 502).

O surgimento da história oriental faz com que temas antes ignorados pelos pesquisadores japoneses, como a história chinesa ou a história coreana, sejam pela primeira vez abordados segundo métodos modernos de historiografia (NAGAHARA 2003, p. 43-45). Não se pode negar, entretanto, que tal divisão entre história japonesa e história oriental contribuiu para a ideia de afastamento do Japão em relação à Ásia, o que dificulta ainda hoje a melhor compreensão de temas de história japonesa dentro de um contexto mais amplo.

\section{A especialização da história}

Com a crescente militarização do Japão, o país tornou-se uma potência imperialista. O ideal de Fukuzawa Yukichi, de abertura e civilização, foi

132 gradualmente abandonado em prol do objetivo do governo de tornar o país uma das grandes potências mundiais da época. E a história não podia mais se limitar à política, sendo necessário abarcar outros ramos como economia, sociedade e cultura para compreender essa nova posição do Japão no mundo. Esta nova geração de historiadores, composta por jovens nascidos sob o regime imperial, sentia necessidade de investigar da ótica da história social, econômica e do direito temas como a revolução industrial japonesa e o acelerado crescimento econômico do país.

Em 1902, Riess deixa o Japão. Para Nagahara Keiji, sua partida marca o fim do período de hegemonia do pensamento positivista academicista e abre espaço para críticas pela nova geração de historiadores. As novas pesquisas partem para uma comparação da sociedade e do sistema legal com os países europeus e os Estados Unidos, buscando definir assim as características que permitiriam ao Japão se desenvolver dentro do modelo apresentado por esses países. Podem ser citados como representanes dessa geração Hara Katsurō, Uchida Ginzō, Fukuda Tokuzō, entre outros (NAGAHARA 2003, p. 43-45).

Uma das marcas dessa nova geração, não somente na história oriental, mas nas ciências históricas em geral, é a mudança de posição em relação à China. Enquanto pensadores do começo da Era Meiji viam a China como a cultura-mãe do Japão, influenciados pelo confucionismo, a nova geração, identificada com ideais imperialistas ocidentais, abordava a China dentro da história oriental como o próximo passo da expansão territorial. Para Nagahara, a pesquisa histórica assume como meta preparar e abastecer a classe intelectual 
de conhecimentos sobre a história chinesa e criar espaço para a anexação (NAGAHARA 2003, p. 53-54).

Outros historiadores seguiam o ideal de Fukuzawa Yukichi de "distanciamento da Ásia e aproximação com a Europa" (Datsua Nyūō). Para eles, a China encontrava-se presa a um modelo asiático que impediria qualquer evolução histórica, o que colocava o Japão em uma posição essencialmente antagônica e mais próxima da Europa (TANAKA 1993, p. 37-38). Tal interpretação alimentou e se alimentava do nacionalismo e da visão da Coreia e da China como inferiores, aprofundando uma visão nacionalista, farisaica e autoindulgente da história, presente na historiografia japonesa do começo do século XX.

Destacou-se nesse período o historiador Hara Katsurō. Formado no Departamento de História Ocidental da Universidade Imperial de Tóquio, após dois anos de intercâmbio nos Estados Unidos, na Inglaterra e na França, volta ao Japão e torna-se professor na Universidade Imperial de Kyoto. Autor de obras de história ocidental, é sua pesquisa sobre o período Kamakura, representada pela obra História do Japão medieval (Nihon Chūsei Shi) que causa maior impacto. Nagahara conta que, para Hara, a contribuição chinesa para a cultura japonesa era superestimada, e foi na Era Kamakura que os japoneses obtiveram autoconsciência de sua cultura, sendo um período de revolução cultural no país e o primeiro grande passo evolutivo da história do Japão (NAGAHARA 2003, p. 48-49).

Essa visão era baseada na história alemã, herdeira do Império Romano e que se descobriu verdadeiramente alemã durante a Idade Média. Retirando daí leis universais de evolução histórica, Hara transplanta para a história japonesa esse processo, descobrindo na Era Kamakura o momento de surgimento de uma cultura verdadeiramente japonesa. Ao contrário da visão da história da civilização de Fukuzawa Yukichi, que ansiava por absorver o que havia de benéfico na Europa e nos Estados Unidos para se concretizar o processo civilizatório japonês, Hara Katsurō reinterpreta a história do Japão para colocar o país no mesmo nível das outras potências (NAGAHARA 2003, p. 47-51).

\section{Conclusão}

A historiografia moderna do Japão nasceu em meio às mudanças da Restauração Meiji. Com disputas ideológicas entre aqueles que formariam o futuro mundo acadêmico japonês, a moderna escrita da história deu seus primeiros passos como história oficial sob o mecenato do regime. Paralelamente, temos pensadores como Fukuzawa Yukichi e Taguchi Ukichi formulando a história japonesa das civilizações, fundada na evolução do espírito humano como objetivo final da história e símbolo de libertação absoluta de todos os povos, e o surgimento da história oriental, que aproximava o Japão de um passado idealizado pan-asiático ao mesmo tempo em que defendia a superioridade do país em relação ao resto do continente.

Apesar da influência da metodologia ocidental, essa recepção teve como pano de fundo as tradições historiográficas chinesas, presentes desde o período Edo. As releituras japonesas formularam linhas fortemente marcadas especialmente pelo confucionismo, fosse por defesa ou negação dessa tradição. 
É interessante notar que obras de pesquisadores como Shigeno Yasutsugu e Kume Kunitake carregam um elevado nível de autocrítica e insatisfação diante das limitações impostas por tal pensamento.

A formação das ciências históricas no Japão coincide com o seu desenvolvimento no Ocidente, assim como o Japão se transforma em Estado moderno ao mesmo tempo que a Alemanha e a Itália. E, tal como em outras áreas do conhecimento, o intercâmbio de especialistas, tanto estrangeiros atuantes no Japão, como japoneses estudando no exterior, parece ter sido fundamental para a transmissão de métodos e ideias.

É inegável que, nesse processo de introdução de métodos científicos europeus, as leituras da história surgidas no Japão carregam em si um alto nível de originalidade. A releitura de historiadores ocidentais foi muito além da simples adaptação de autores estrangeiros por estudiosos japoneses. Essas reflexões podem ser percebidas nas obras de Fukuzawa Yukichi, Taguchi Ukichi, Shigeno Yasutsugu, Kume Kunitake, Naka Michiyo, etc. A presença de linhas de pensamento diferentes das existentes na Europa durante o século XIX parece ter levado a um conflito de ideias e a uma reflexão aprofundada, e a comparação de autores desse momento oferece um rico campo para futuras pesquisas e reflexões no campo da história da historiografia.

\section{Referências bibliográficas}

CHAN, Wing-tsit. A Sourcebook of Chinese Philosophy. Princeton: Princeton University Press, 1963.

FUKUZAWA, Yukichi. Bunmeiron no Gairyaku (Descrição da teoria da civilização). Tóquio: [s. ed.], 1875. 6v.

GORDON, Andrew. A modern history of Japan: from Tokugawa times to the present. Nova Iorque: Oxford University Press, 2003.

HYŌDŌ, Hiromi. Rekishi ni okeru "Kindai" no Seiritsu: Bungaku to Rekishi no Aida (A formação do "moderno" na pesquisa histórica: entre a Literatura e a História). Seijō Kokubungaku Ronshū (Revista de Teses de Literatura Nacional Seijō), Tóquio, Vol. 25, p. 255-280, 1997. Disponível em: http:// www.seijo.ac.jp/graduate/gslit/orig/journal/Japanese/pdf/sbun-25-08. pdf. Acesso em: 13 de junho de 2011.

ISHIDA, Ryūjirō. Kōkoku Chishi no Hensan: sono keii to shisō (A edição do Relatório Topográfico do Império: seu processo e pensamento). Hitotsubashi Daigaku Kenkyū Nenpō, Shakaigaku Kenkyū, Tóquio, Vol. 8, p. 1-61, 1966.

KADOWAKI, Teiji. Kangaku Akademizumu no Seiritsu (A formação do academismo governamental). In: REKISHIGAKU Kenkyūkai; NIHONSHI Kenkyūkai (eds.). Nihon Rekishi Kōza 8 (História do Japão volume 8). Tóquio: Tóquio Daigaku Shuppankai, 1961. 
KANAI, Madoka. Oyatoi Gaikokujin 17: Jinbungaku (Estrangeiros contratados Vol. 17 - Ciências humanas). Tóquio: Kashima Shuppankai, 1976.

KUME, Kunitake. Shintō ha Saiten no Kozoku ("O xintoísmo é um rito antigo"). In: TANAKA, Akira; MIYACHI, Masato (eds.). Rekishi Ninshiki (A consciência histórica). Tóquio: Iwanami Shoten, 1991.

MEHL, Margaret. History and the State in Nineteenth-Century Japan. Nova Iorque: Palgrave Macmillan, 1998.

. Meiji Shigaku ni okeru Doitsu no Eikyō: Dore hodo Igi aru Eikyō datta no ka? (A influência alemã na historiografia da era Meiji: quão importante foi esta influência?). In: TŌKYŌ, Daigaku Shiryō Hensan Jo (ed.). Rekishigaku to Shiryō Kenkyū (A pesquisa histórica e de fontes). Tóquio: Yamakawa Shuppansha, 2003.

NAGAHARA, Keiji. 20 Seiki Nihon no Rekishigaku (A historiografia do Japão no século XX). Tóquio: Yoshikawa Kōbunkan, 2003.

NIHON REKISHI GAKKAI (ed.). Nihonshi Kenkyūsha Jiten (Dicionário de historiadores Japoneses). Tóquio: Yoshikawa Kōbunkan, 1999.

NUMATA, Satoshi; MOTODA, Takehiko. Motoda Nagazane Kankei Monjo (Documentos sobre Motoda Nagazane). Tóquio: Yamakawa Shuppansha, 1985.

SATŌ, Shinobu et al. Shōsetsu Nihonshi Kenkyū (Estudos detalhados de pesquisa em história japonesa). Tóquio: Yamakawa Shuppansha, 2008.

SCHNEIDER, Axel; TANAKA, Stefan. The Transformation of History in China and Japan. In: MACINTYRE, Stuart et al. The Oxford History of Historical Writing. Volume 4 (1800-1945). Londres: Oxford University Press, 2011.

SHIGENO, Yasutsugu (aut.); SAPPAN, Shi Kenkyūkai (ed.). Shigeno Hakase Shigaku Ronbunshū (Coletânea de teses de história do doutor Shigeno). Tóquio: Yūzankaku, 1938-1939.

SHIGENO, Yasutsugu. Shigaku ni Jūji suru mono ha shikōshihei narazarubekarazu (Aquele que segue a ciência histórica deve ser justo). In: TANAKA, Akira; MIYACHI, Masato (eds.). Rekishi Ninshiki (A consciência histórica). Tóquio: Iwanami Shoten, 1991a. Discurso proferido em $1^{0}$ de novembro de 1889.

. Kokushi Hensan no Hōhō wo Ronzu (Tese sobre métodos de edição da história nacional). In: TANAKA, Akira; MIYACHI, Masato (eds.). Rekishi Ninshiki (A consciência histórica). Tóquio: Iwanami Shoten, 1991b.

TAGUCHI Ukichi. Nihon Kaika Shōshi (Pequena história da civilização do Japão). Tóquio: Kōdansha Gakujutsu Bunko, 1981.

TANAKA, Akira; MIYACHI, Masato (eds.). Rekishi Ninshiki (A consciência histórica). Tóquio: Iwanami Shoten, 1991.

TANAKA, Stefan. Japan's Orient - Rendering Pasts into History. Berkeley, Los Angeles e Londres: University of California Press, 1993. 
WATANABE, Hiroshi. Nihon Seishi Shisō Shi (História do pensamento político no Japão). Tóquio: University of Tóquio Press, 2010.

ZERFFI, Gustav. Shigaku (História). In: TANAKA, Akira; MIYACHI, Masato (eds.). Rekishi Ninshiki (A consciência histórica). Tóquio: Iwanami Shoten, 1991. 